\title{
Telehealth Practically Speaking: Is New York at a Tipping Point?
}

Ester Horowitz

Abstract: Medical care is becoming cost prohibitive. Responsiveness and access to care are more difficult. There are reasons and perspectives as to why and how to solve this issue. Yet, despite advances in medicine and technology, delivery of care is more complicated for the average consumer and less rewarding for doctors..

We yearn for the "Norman Rockwell" and "Marcus Welby, MD" experience of the mid20th century that made society feel they were in good hands and made doctors feel valued in their chosen profession. Enter telehealth and telemedicine. The second fastest growing industry, giving consumers and practitioners more of what they desire: a better experience.

Telehealth is defined as the use of devices to measure body responses and conditions remotely. ${ }^{1}$ Telemedicine is delivery of care using remote methods. ${ }^{1}$ Collectively they are referred to as telehealth. Other references may include: mHealth, Internet-of-Things or loT, and digital health.

In 2003, New York State approved telehealth for Medicaid, to support rural areas. The State continues to address it with newer guidelines that include population dense facilities such as article 28s and FQHCs. ${ }^{2}$ Most states, including New York, now recognize telehealth by mandating that it be covered as a service under commercial insurance. New York mandated the coverage effective January 1, 2016. ${ }^{3}$ New York State Telemedicine Bill SB 7953, pending since May 31, 2016, expands the definition to include economic parity equal to face-to-face office visits for those commercially insured. ${ }^{4}$

Almost fifteen years since New York State approved telehealth, the ability to reach its full potential is just starting. Market forces, medical economics, and technological advances in the past ten years since the introduction of smart phones and Facebook have created the perfect environment to bring back the "Norman Rockwell" experience 
by removing gaps caused by time, distance, logistics, and funds. It's done without losing the advances medicine achieved to support better care and without losing the communication value or privacy sacrosanct in doctor-patient interactions.

It is also stabilizing or reducing the cost of care ${ }^{5}$ and paying doctors for efforts currently not covered. Patients are more open, willing, and adaptive than their personal physicians. ${ }^{6}$ A phenomenon that is leading patients outside of their traditional doctor's silo as a result.

Kevin Volpp, MD, PhD, Director of the Center for Health Incentives and Behavioral Economics suggests that the key is recognizing what patients want-to be healthy and not consume more services. ${ }^{7}$ He states that technology should be designed for patient convenience rather than providers and it be simple. He suggests using incentives to keep people healthy as the method to provider success, rather than treating them only when they are sick.

American Well, Doctor on Demand, Medici, Second MD, CareSpan, Genoa, and others are leading the way, proving that Americans are hungry for and flocking to alternatives outside of health systems and traditional doctors' offices. Urgent Care centers and concierge practices are two answers responding to the need, but these too are more expensive and less available compared to the flexibility of telehealth as a consultative service $24 / 7$. Telehealth is a just-in-time tool and strategy that is more responsive at lowers cost without compromising good care.

\section{Telemedicine Proactive Applications}

Done right, telemedicine is a tool that determines if a patient needs escalation to more complex interventions that face-to-face office visits satisfy. This model offers patients control and decision-making they currently lack. It helps them determine quickly whether their care is something warranting a doctor's office visit, which generally involves invested time away from work and family; something favored by employers and family caregivers. ${ }^{8,9}$ 
Taken further, it supports health organizations and providers' needs to better manage staff, labor costs, planning, and time usage requirements in population health management. ${ }^{10}$ From a chronic care perspective, it can meet state and federal mandates to monitor care proactively, including value based models of care.

Insurance carriers benefit by better communication methods that engage patients and their care givers to act appropriately to seek the right care, at the right time, in the right setting, for the right reasons. It better manages specialty referrals, pharmacy, ancillary costs and "gaming" designed to increase reimbursement costs.

New York hospitals have started telemedicine integration for in-patient care since 2014, and some are now considering how to capitalize on it for their out-patient services. Their needs are more complicated, requiring large investments of time and equipment to accomplish successful outcomes one department at a time. New York State has approximately 120 hospitals out of 226 reported to be involved in some form of telehealth. ${ }^{11}$

Independent providers have the greatest competitive advantage using telehealth than their hospital counterparts. Hospitals are larger and too institutionalized to offer better value and better non-emergent response to patients and insurance companies paying the bill. The emergency room (ER) is still the primary point of entry, despite enormous efforts to reduce unnecessary ER care. It is possible for independent physicians to earn $\$ 180,000$ annually part-time to care for patients using telehealth strategies based upon current trends. It's also not hard or costly.

Newer low cost or no cost tools help independent physicians have telemedicine strategies that foster patient loyalty to them over an institutionalized health and hospital system. Medici's smartphone app is one example. Telehealth fosters patient loyalty by maintaining the emotional and physical connection. It is the emotional and physical disconnects that causes patient losses. Fostering patient loyalty creates better ability to compete in New York's hospital driven market. 
All healthcare stakeholder can benefit from telehealth. The only thing holding them back is mindset.

In the next ten years, telehealth can and will change the way we deliver care. It will be done by necessity, patient demand, and the technological sophistication, as well as comfort level of our younger population. According to the North Country Telehealth Partnership, representing the New York based care community, growth of telemedicine use in rural areas alone is almost 20 times greater from 2014 to 2016 than from 2003 to 2014.

\section{Telehealth Device Proactive Applications}

The fait accompli pronouncement is supported by the simple example that baby boomers are an adaptive generation, changing society at every stage of life since birth. They want to remain in constant communication with their grandchildren and grown children who represent your millennials, generation $X$ and Yers-the very population that makes technology routine, accelerating remote interactions comfortably. The same motives and methods that has all of them texting on Facebook, using tablets, smartphones, downloading apps, and video chatting to stay connected exists in telehealth. There are no limits based on age or economics, including frail elderly because their caregivers and support systems are technologically comfortable.

Much like smart phones and satellites transformed how we communicate, telehealth will change how we participate in health services. Telehealth devices designed for consumers will evolve the way smart phones have. Think about how the Sony Walkman evolved into the IPod, and now the IPod is integrated into today's smartphone. Think about how fax machines evolved to faxes sent over VOIP (Voice over Internet Protocol) services. Wearable fitness trackers, smart watches, and many health apps are just the beginning. Tying halter monitors, blood pressure cuffs, scales, medication management devices and the software that supports them is another indication.

Alexa and Siri are examples of early artificial intelligent tools that lends themselves to accelerating telehealth without violating privacy because the consumer controls them. 
More information about specific devices and remote patient monitoring platforms for chronic disease care is available online at mHealth Intelligence. The article "Top 10 Remote Patient Monitoring Solutions for Hospitals" by Thomas Beaton provides quick insights. $^{12}$

Ten years from now telehealth devices will be a part of the design in every "smart home" to support the home-bound care trend now growing as baby boomers age and as part of chronic care management of diseases like diabetes, multiple sclerosis, chronic obstructive pulmonary disease, cardiovascular disease, and arthritis, to name a few. ${ }^{13}$ Josh Zinder, an award-winning architect and designer of JZA+D in Princeton, New Jersey, who was featured in Architectural Digest a few times, states telehealth devices will be possible in the next five years. It is not inconceivable to consider the same would be true in business as employers find creative ways to keep their work force healthy and productive.

\section{The New York Experience: Pro and Cons}

New York is the most densely diverse market that benefits from the elimination of care barriers. Its cultural and geographic diversity is both a challenge and an opportunity.

Population health and value-based care involving DSRIP (Delivery Service Reform Incentive Payment) ${ }^{14}$ and Medicare have taken up the most time and discussion among the New York delivery of care community over the past 24 months. All of which is to accomplish the goals established by the "triple aim." ${ }^{15}$ The triple aim is to reduce unnecessary costs, increase patient satisfaction, and increase quality of care through proactive and preventive responses. Telehealth is a value driven strategy to respond in meaningful ways to this, including cultural sensitivities.

While not every specialty nor every medical need is appropriate for telehealth services nor should it be, the majority of the common needs across most specialties and disease states are. Ideally providers can use telehealth as an integration tool to optimize their patient's care and outcomes. Dr. Volpp states that there is already an ecosystem of 
devices, tools, strategies, and provider feedback loops that managed chronic disease more efficiently than the reliance on current chronic care methods.

A chronic care patient may have as many as 22 entities involved in their care at one time. ${ }^{16}$ It's an effective tool to better manage and plan care in support of catastrophic and chronic patient needs including the use of care teams and integrating family and quality of life goals.

Research shows that New York currently has a high demand for nurse practitioners and immediate care providers. Urgent care offices and chronic care programs are having difficulty fulfilling the growing slots based upon a model of care that continues to apply $20^{\text {th }}$ century expectations now becoming obsolete more of the time. It's not filling the escalating gaps in care as more and more patients demand home bound choices.

It's an industry issue for institutionally designed and driven mindsets like New York. The provider community is "risk adverse" making them reluctant change agents, preferring to uphold a static gold standard that by its very nature is scientifically designed to evolve. A point that gets lost when attempting to create new business models.

Practitioners often build business models, aka practices or lines of services, on the assumption that the practice of today should last the length of a career without recognizing the laws of nature, science, and business obsolescence. New York's health market is in rapid-cycle change requiring testing gold standards and assumptions annually to adapt. It is not uncommon for practitioners to wake up a few years later not understanding how and why they have a declining organization.

\section{A Recent New York Project}

Experience reveals that providers who deliver care closer to New York City are more open to adapting newer ideas than providers found in suburban areas. Recent efforts to implement telehealth services in Nassau, Suffolk, Queens, and Brooklyn demonstrated that there are more open-minded practitioners found in Queens and Brooklyn than their equally capable Long Island peers. Queens and Brooklyn are the most culturally diverse 
regions in the United States with strong influences on how care is delivered, by whom, and under what context.

Explanations given for non-adoption include the inability to add telemedicine to their already crowded and high demand practice. From the practitioner's vantage point, it's physically impossible to implement. The assumption is that telehealth adds more visits without realizing that the application better manages all visits. Providers with that mentality assume their patients don't want to use the technology either. Instead they assume patient prefer to sit in an office for two or more hours waiting to be seen face-toface. That may be true for patients with lifestyles that crave personal connections and use their doctor's office visits to compensate. It surprises providers how many of their patients respond positively when shown how telehealth works.

Generally, when providers are comfortable, their patients follow. Especially if providers have established relationships with patients longer than two years. Adoption generally comes down to two things. The first is how it gets paid, by whom, when, and how much. The second is how easy or difficult it is to integrate.

Other objections included the assumption that there is a need to access electronic health records, patient portals, or perform double documentation. Medici proves that it isn't necessary and so does HouseCall TeleMed and Genoa. Further prompting reveals concerns with medical liability but every time a provider calls the medical malpractice carrier as part of their due diligence, they are told it's fine. The providers that says no, says no simply because it's out of their comfort zone.

Telehealth is evolving and becoming more sophisticated to accommodate the different community expectations and provider requirements. Providers and patients comfortable with audio and/or video chat as a step-up solution to symptom response is now more common place and continues to grow. Younger New Yorkers are engaging and influencing their elders but not telling their providers about it.

Providers who prefer measuring common body systems as part of their consult can accomplish the goal in the right situations and with the right logistical strategies. UltiMed 
Health Services offered by the Virtual Health Group is a start-up proving that providers are ready.

Devices are not only available for professional usage purposes, but so are consumer versions. The most recent experience to implement telehealth services in private practice settings and hospital systems shows that this strategy is a more comfortable point of entry for telehealth adoption.

Historically New York is the epicenter of innovation and venture capital according to Tory Cenaj, Publisher of Telehealth and Medicine Today. Historically too, New York is not a test market for new products and services. Florida, Texas, Minnesota, Ohio, and California are more adventurous as evidenced by the number of growing telehealth companies springing from these states.

But since 2014, several New York hospitals have begun dipping both feet more into the telehealth pool. Mount Sinai, Beth Israel, and New York Presbyterian are using telehealth as strategic tools to better manage and organize inpatient care. New York Presbyterian just announced it was adding telehealth to its pediatric urgent care unit. Northwell Ventures is expanding beyond its inpatient services outward as part of its investment in Avizia. St Mary's Hospital for Children was the first hospital awarded \$1M grant in 2015 to implement telehealth. Morgan Stanley offers telehealth as an employee benefit as do one-third of all employers according to American Well. ${ }^{17}$

Local organizations such as Healthcare Partners, Quality Health Plans of New York, United Health Plans, Humana, WellPoint, Aetna, and some accountable care organizations now use telehealth as part of their chronic care strategy. Castle Connolly, recognized as the publisher of America's Top Doctors ${ }^{\mathrm{TM}}$, has entered into an arrangement with CareSpan to support their market expansion. Oscar Health uses telehealth as a core strategy to support care.

Yet, if you talk to mainstream metro New Yorkers and most industry professionals about telehealth the response is generally "Wait? What?" New Yorkers don't realize they already engage in telehealth voluntarily in some manner because it is not referenced 
under the broader category nor is it coming directly from or endorsed by mainstream providers and health organizations they commonly engage.

Common business thinking supports the premise that once population awareness and acceptance exceeds $32 \%$ penetration, demand builds exponentially. The New York delivery of care community is not there yet, but it is at the tipping point.

Despite political insecurities permeating the industry in New York, even with a strong governor's staunch stance about health policy, the simple fact remains that healthcare costs can no longer be sustained here. The labor and investment to support current initiatives have not proven to drive the costs down yet and the clinical labor demands go unfulfilled.

It is complicated by the fact that more than $50 \%$ of the provider community is over 55 years old looking to retire with fewer newly minted practitioners taking their place. It's resulting in longer waits to be seen and shortages both in primary care as well as some specialties. The Association of American Medical Colleges predicts that by 2020 the U.S. will be short more than 45,000 primary-care doctors-those who practice internal medicine, family medicine and pediatrics. New York is feeling the pain even in suburban and urban areas that boast a density of doctors.

\section{Summary}

Most of the solutions offered in the past 10 years are based upon business models, assumptions, and desires that foster late $20^{\text {th }}$ century mindsets but doesn't change the experience for the better. It's more of the same packaged differently. Like the reemergence of Urgent Care Centers now involved in mergers and consolidation, unless they engage in telehealth, be warned that they are "just for now" models parading around as great ideas. They have a limited shelf life as more and more consumers decide to take control about how they want to experience care.

New York has always been active in setting standards and mandates for care. As one of the first to implement community rating standards well before Obamacare, they created their own ACA (Affordable Care Act) exchange since their mandates were well ahead of 
the rest of the United States. New Yorker's insurance premiums have risen but not in the same dramatic fashion as other states. Obamacare required the other states to elevate their requirements to New York's level.

New Yorkers are not shy about seeking alternatives and expecting more. Do-it-yourself, pay-as-you-go, doctor, facility, and insurance shopping, and other non-provider directed health related activities are normal. Laws designed to educate New Yorkers about how many calories they consume outside of the home, where they can smoke, or how much they can drink are designed to link business and consumers together to collectively take control of health and make it a normal societal responsibility. It results in better decision making and encourages better habits.

From a delivery of care perspective, New Yorkers are weary of promises to protect their medical best interests which are abundantly diverse. They are becoming more and more weary of how bogged down and complicated the process is to access care including interacting with insurance companies.

The market may be hospital controlled, but historically hospital systems are held down by their own weight to implement meaningful change in reasonable time frames at reasonable costs. The old joke about how many people it takes to change a light bulb applies because of the number of people that need to be involved in the decision, planning, and implementation.

The independent physician market is more flexible but stymied by lack of resources and time having bought into the volume approach to economic survival. Historically too, most are a breed that leaves innovation up to others that they then copy without realizing the "me too" approach is not always appropriate. In fairness, there are less entrepreneurs and disruptive innovators in every industry.

Concierge practices help a population that can afford it, but like their urgent care counter-parts, it too is ripe for obsolescence if it doesn't adapt its model to include telehealth. Howard Reis, President of HealthePractices presented supporting evidence of this during his presentation at the American Telemedicine Association meeting held 
in Los Angeles in 2015. Ask a New Yorker their opinion and they will tell you that health is $24 / 7$ not a 9am-6pm, 8am-8pm or 12pm-12am effort. It leaves New Yorkers fending for themselves and questioning why some haven't recognized it or if they have why they are falling short.

Telehealth is succeeding in New York not because the delivery of care community is leading the way. And not because they aren't living up to a standard of excellence or attempting to do more within infrastructures they already have. New York is a world class epicenter for healthcare.

It's changing because healthcare and technology separately and simultaneously are rapidly changing opening choices not available five years ago. It's changing because legislation is encouraging it. At the heart of it all are the consumers who are demanding something better that is less complicated, takes less time, and it's offered at reasonable rates.

New Yorkers aren't waiting for industry and political leaders, nor their own personal doctors to figure it out. They are carving their own paths and defining how they want their healthcare experience to happen. This includes individuals who live here, work here, and visit here.

Astute, independent, medically trained, and technically capable market disrupters recognize it and they are responding to these desires in other parts of the country but questioning if New York is ready for them. To be clear consumer need is different from consumer desire. Any seasoned sales or business development expert will attest to the fact that desire eclipses need.

A recent example cited by McKesson's report released July 5, 2017 entitled "The Evolution of Telemedicine", demonstrates that telehealth penetration among Medicaid recipients is far smaller than the general population. It was assumed they needed it more, and that is true. New York has the largest Medicaid population and offers the most benefits under the program. But Medicaid patients aren't accessing it in the same volume as non-Medicaid despite the fact they have smart phones, are technology 
connected and have access to care. They don't have the same desire to do so just yet but evidence is demonstrating that it's changing as they are more exposed. The lesson is that desire moves markets exponentially.

Disrupter success is now replicating and improving because main stream consumers want it. Simply stated, they are changing the consumer experience for the better incorporating Rockwellian features. The heart-beat of real innovation is how society is lifted to a new standard by the effort. To repeat, telehealth is the second fastest growing market, proving that. ${ }^{18}$

The delivery of care community in New York is now catching up. They are waking up, organizing, legislating, listening, collaborating and implementing. The delivery of care community now sees they will lose their patients if they don't.

For innovators who question if, and, or when they should enter the New York market, it's suggested that now is the time. The telehealth innovators who live and work in the trenches of New York will tell you that there is a tidal wave growing that will turn into a tsunami in a few short years.

For more information about telehealth go to the American Telehealth Association, Telehealth and Medicine Today, mHealth Intelligence, or HIMSS online. For more information that is New York specific try HANYS.org, health.ny.gov, MedCity News, and The Northeast Telehealth Center. Linkedln and The Health Club New York are excellent networking venues to speak to innovative and accomplished professionals. For introductions to the club or telehealth leaders you may want to know, email a request to the author,witsowitz@verizon.net. 


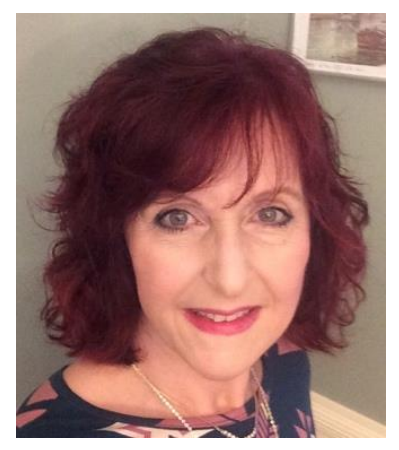

Ester Horowitz, CHC, MBA, has a BS in social work, an MBA in business and certification in healthcare compliance. She began her career in healthcare in 1984 creating a grass roots non-profit support group for bipolar disorder supporting 200 individuals and families affected by the disease in her local area. Ms. Horowitz went on to pioneer one of the first Medicaid managed care programs in downstate New York enrolling a historic 8700 members its first year by developing a first-of-its-kind marketing program and strategies in collaboration with local government agencies and insurance. Ms. Horowitz continues to work with health organizations large and small, evolving and growing services and products that improve experiences and outcomes for patients and the providers that serve them. Her most recent experiences includes information security, population health management, and telehealth. Ms. Horowitz growth expertise is multifaceted to enable best outcomes for emerging and growing lines of business. Examples include business model testing; market and growth strategy development; and implementation, strategic collaborations; and partnerships; education; and client acquisition and retention. Ms. Horowitz is a public speaker, published author, and cited expert for notable organizations such as Healthleaders.com, Society of Human Resource Managers, The Coding Institute, Association of Certified Fraud Examiner, Texas DO, New York State Society of CPAs, and New York, Westchester, and Nassau Bar Associations among them.

\section{References}

1. Center for Connected Health Policy. NY State Law Telemedicine/Telehealth Definition. 2017. URL: http://www.cchpca.org/ny-state-lawtelemedicinetelehealth-definition. 
2. Healthcare Association of New York State. Telemedicine/Telehealth Payment and Policy. 2017. URL: Hanys.org/telemedicine.

3. Lacktman NM, Rosen EF. Changes to New York Telehealth Coverage Coming Soon. Foley \& Lardner, LLP. 2015. URL:

https://www.healthcarelawtoday.com/2015/10/19/changes-to-new-yorktelehealth-coverage-coming-soon/.

4. Lacktman NM, Rosen EF. New York Legislature to Require Payment Parity for Telehealth Services. Foley \& Lardner, LLP. 2015. URL:

https://www.healthcarelawtoday.com/2016/06/15/new-york-legislation-to-requirepayment-parity-for-telehealth-services/.

5. LeadingAge. How Telehealth is Helping the VA Reduce Health Care Costs. 2014. URL: http://www.leadingage.org/how-telehealth-helping-va-reduce-healthcare-costs.

6. McKesson. The Evolution of the Telemedicine Market. McKesson. 2017. URL: http://www.mckesson.com/blog/the-evolution-of-the-telemedicine-market/.

7. Volpp KG, Patient Engagement and Behavioral Insights-What People Want is Health. NEJM Catalyst. 2016. URL: http://catalyst.nejm.org/patient-engagementbehavioral-insights-time-recognize-health-people-want/.

8. Chi N-C, Demiris. A systematic review of telehealth tools and interventions to support family caregivers. Journal of Telehealth and Telecare. 2014. URL: http://journals.sagepub.com/doi/abs/10.1177/1357633x14562734?journalCode=jt ta.

9. Makowka J, Lau T, Kachnowski S, et al. Caregivers \& Technology: What They Want and Need: A Guide for Innovators-Research from A Nationally Representative Sample of America's 40 Million Family Caregivers. Telehealth and Medicine Today. 2017. URL:

http://www.telhealthandmedtoday.com/caregivers-technology-what-they-wantand-need-a-guide-for-innovators-research.

10. Stanzler L. Telemedicine for population health: the future of telehealth. American Well Blog. 2017. URL: https://www.americanwell.com/telemedicine-forpopulation-health-the-future-of-telehealth/. 
11. CHWS. An Exploratory Study of the Use of Telehealth Services by Federally Qualified Health Centers and Hospitals in New York State. School of Public Health, University of Albany, State University of New York. 2015. URL:

http://www.chwsny.org/wpcontent/uploads/2015/11/Telehealth Services NY 2015.pdf

12. Beaton T. Top 10 remote patient monitoring companies for hospitals. mHealth intelligence. 2017. URL: https://mhealthintelligence.com/news/top-10-remotepatient-monitoring-solutions-for-hospitals.

13. Demiris G. Digitally augmented homes; telehealth for smart homes. 2014 NRTRC Telemedicine Conference, Portland, Oregon. 2014. URL: https://www.nrtrc.org/content/presentationfiles/Digitally\%20Augmented\%20Homes\%20\%20Telehealth\%20for\%20Smart\%2 OHomes.pdf

14. New York State, Department of Health. Delivery Service Reform Incentive Payment. 2014. URL: https://www.health.ny.gov/health care/medicaid/redesign/dsrip/overview.htm.

15. Reich JJ, Osborne TF. Home telehealth and the triple aim. Telehealth and Medicine Today. 2017; 2(4). URL: http://www.telhealthandmedtoday.com/hometelehealth-and-the-triple-aim/.

16. Copy of the diagram is available upon written request.

17. Modahl M, Natoli S. Telehealth Index: 2016 Employer Benchmark Survey. American Well. 2016. URL: http://go.americanwell.com/rs/335-QLG882/images/Employer-Benchmark-Survey-eBook.pdf.

18. Winfrey G. The 5 Fastest Growing Industries in the US. Inc. 2015. URL: https://www.inc.com/graham-winfrey/the-5-fastest-growing-industries-in-theus.html.

This is an open access article distributed in accordance with the Creative Commons Attribution Non Commercial (CC BY-NC 4.0) license, which permits others to distribute, adapt, enhance this work non-commercially, and license their derivative works on 
different terms, provided the original work is properly cited and the use is noncommercial. See: http://creativecommons.org/licenses/by-nc/4.0.

Category: Interview and Opinion

Tags: application, decision-making, hospital, New York, telehealth, telemedicine, tipping point 